Article

\title{
The Joy of Having a Book in Your Own Language: Home Language Books in a Refugee Education Centre
}

\author{
Nicola Daly ${ }^{1, *(\mathbb{D})}$ and Libby Limbrick ${ }^{2}$ \\ 1 School of Education, University of Waikato, Hillcrest, Hamilton 3240, New Zealand \\ 2 Faculty of Education and Social Work, University of Auckland, Auckland, Auckland 1010, New Zealand; \\ 1.limbrick@auckland.ac.nz \\ * Correspondence: nicolad@waikato.ac.nz
}

Received: 20 August 2020; Accepted: 9 September 2020; Published: 15 September 2020

\begin{abstract}
In 2018, Aotearoa/New Zealand increased its annual refugee quota to 1000. When refugees arrive in Aotearoa/New Zealand they spend six weeks in a resettlement programme. During this time, children attend an introduction to schooling. First language (L1) literacy support for children experiencing education in a medium that is not their Home Language has been identified as essential for children's educational success. This knowledge is reflected in Principle 4 of the International Literacy Association's Children's Rights to Read campaign, which states that "children have the right to read texts that mirror their experiences and languages...". In 2018, the International Board on Books for Young People (IBBY)-Yamada Foundation granted funding to IBBY in Aotearoa/New Zealand (IBBYNZ)/Storylines to supply books in the Home Languages of the refugee children in the introduction to school programme. Over 350 books were sourced in a range of languages including Farsi, Arabic, Tamil, Punjabi, Burmese, Karen, Chin, and Spanish. In this article, the sourcing of these books and their introduction to children in a refugee resettlement programme is described. Interviews with five teachers in the resettlement programme concerning the use of the books and how children and their families have been responding are reported. Future programme developments are outlined.
\end{abstract}

Keywords: home language; refugee education; picturebooks; children's right to read; identity

\section{Introduction}

In 2018, Aotearoa/New Zealand increased its refugee quota to 1000 persons per year [1]. When refugees arrive in Aotearoa/New Zealand they spend six weeks in a resettlement programme. During this time, the children attend a school at the refugee resettlement centre within the requirements and oversight of the New Zealand Ministry of Education. Within the refugee resettlement centre where the school programme is held, there are also programmes for adults relating to English language and living in New Zealand. The school is well resourced and supported by interpreters. The aim of this programme is to familiarise the refugee families and their children with the cultural patterns and expectations of the Aotearoa/New Zealand school system, and also to assess the specific learning needs of the children before they travel to the Aotearoa/New Zealand city in which their family will be settled.

In 2016, the Storylines Children's Literature Trust of Aotearoa/New Zealand, the New Zealand section of the International Board on Books for Young People (IBBY), hosted the biennial congress of IBBY at which a number of papers described the extreme deprivation of their language and identity that is experienced by refugee children throughout the world. This anomie was partially attributed to the absence of culturally contextualised books and stories in Home Languages. The congress discussions, including the final address of the president, challenged the IBBY in Aotearoa, New Zealand, (IBBYNZ) 
to review what was happening for the increasing numbers of children arriving in Aotearoa/New Zealand as refugees from many parts of the world.

When IBBY promoted its annual IBBY-Yamada Foundation grant in 2017, the opportunity arose to meet this challenge. The Yamada grant provides contestable funds to support the development of a book culture for children around the world [2]. One of the authors and a colleague, both of whom were involved with the school and early childhood programme at the refugee centre, met with the director of the refugee education centre to see if there was any support that the IBBYNZ could give. It was evident that, despite the existing programme at the refugee education centre being rigorous, well-resourced, and supported by interpreters, there were few books in the Home Languages of the refugee families. The refugee families arriving at the centre, having experienced many years of disruption, brought with them few resources in their Home Languages; in some instances, other than their immediate family, they had had few opportunities to use their language since leaving their home country. Having established a clear need for books in the Home Languages of the children at the refugee education centre, IBBYNZ/Storylines applied for the IBBY-Yamada Foundation funding and in 2018 was awarded $\$ 5000$ USD to supply books in the Home Languages of the children at the centre for refugee education. A year later, following the report of the first year, a further grant of $\$ 10,000$ USD was awarded to the project to enable the continuation and extension of the work.

In this article, we will first present some literature supporting the need to support Home Languages, and then describe programmes which have been developed to provide books in Home Languages for children from refugee communities around the world. We will then present the voices of five teachers describing their experiences in the early stages of this programme.

\section{Literature Review}

We use the term 'Home Language' to refer to the language used by the refugee family at home among family and community members. Generally, the Home Language of a refugee family is different to the language being used as the medium of instruction in an educational setting. In the past, there has been the mistaken belief that it was best to discourage the use of Home Languages in school in order to support children's acquisition of the language of instruction. Discouragement of the use of Home Languages has sometimes involved corporal punishment, and there are many accounts of this in, for example, the case of indigenous languages in colonial settings [3]. While the use of Home Languages among refugee communities does not have the same implications for a language's vitality as is the case for the use of indigenous languages, it does have similar implications for the literacy development and educational success of the children.

Negative attitudes towards the use of Home Languages in schools have been documented, even in recent times. For example, in an overview of the themes evident in five separate studies of the experiences of Pāsifika students in Aotearoa/New Zealand classrooms, Hunter et al. [4] revealed a range of teacher attitudes to using Home Languages in the classroom, from those who supported this approach and saw its benefits, to those who were still advising parents to use English at home and those who were framing the lack of English as the reason for learning difficulties. Similarly, a survey of Flemish secondary school teachers showed that only $5 \%$ of teachers supported the inclusion of mother tongue in the education of students, and a third of respondents thought it would be in the best interests of students to punish them for using their Home Language at school [5].

The provision of books in the Home Languages of children in the refugee centre education programme is supported by three themes in the literature: (1) The power of children's literature with respect to increasing understanding of the experiences of refugees, both prior to and during resettlement; (2) the importance of maintaining the Home Language of children whose language is not the medium of educational instruction; and (3) the potential of Home Language children's literature in supporting the educational progress of refugee children. 


\subsection{Children's Literature Supporting Understanding of the Refugee Experience}

The use of children's literature to both reflect their world for them, and to introduce to other readers the experiences of refugee children, has been well documented. Brooking [6], for example, unpacks seven picturebooks and two non-fiction articles in a children's educational journal to explore how these forms of children's literature can be used to develop empathy and an understanding of the experiences of refugees, such as how the refugee experience might make a person think and feel. She argues that careful text selection of children's books reflecting authentic refugee experiences can support the integration of refugee children in the classroom and support the development of a human rights culture within educational settings. She continues that 'the integration of child refugees within the school system is integral to their future successful outcomes and education needs to be considered in the same way as shelter or food".

Similarly, Arizpe [7] examines a corpus of seven children's literature texts telling refugee stories. Arizpe analyses how text and image allow the reader to understand three main aspects of the experiences of refugees related to the importance of appropriate footwear, the experiences of pain and physical discomfort, and the discourse of forced migration. Like Brooking, Arizpe argues for the pedagogical power of children's literature for supporting the development of understanding and empathy. In both cases, Arizpe and Brooking show the potential of children's literature to provide a window [8] into understanding the experiences of refugee children. The books reviewed by Brooking and Arizpe focus on telling the stories of refugee children, rather than stories using Home Languages. As well as validating and supporting the voice of the refugee child in the classroom, the use of literature featuring Home Languages also allows all students to see and hear a range of voices in the classroom [9], a very important step in children's awareness of the link between language, education, and power.

\subsection{The Importance of Maintaining the Home Language of Children}

Research also supports continuing first language (L1) literacy development for children experiencing education in a language medium that is not their Home Language [10-13]. It is well established that children's home language is important not only for their language development but also for their cognitive development and academic achievement. Indeed, research shows that children who do receive some education in their Home Language are more successful than those who do not [14]. This knowledge is reflected in Principle 4 of the International Literacy Association's ten principles of the Children's Rights to Read campaign, which states that "children have the right to read texts that mirror their experiences and languages..." [15].

This principle acknowledges that the provision of books in the Home Languages of refugee children provides a context for maintaining their Home Language; it also conveys to the refugee child that they, their language, and their culture are valued by the educational contexts and community in the country in which they now live. Furthermore, texts in Home Languages provide families with familiar images, vocabulary, stories, and orthographies to strengthen their sometimes vulnerable family and ethnic identity in what can be overwhelming influences of the majority language and culture [10].

Ball [10] argues that absence of their Home Language in their new community means that young migrants feel their language and culture is considered of no value. This view is acknowledged by Brown-Hamilton [16] when discussing the difference between assimilation and integration of refugees. She reports on a project in the Netherlands to support refugee children to maintain their Home Language and culture through providing books so that parents can read to children in their Home Language while adjusting to life in a new country. As Nola Harvey, said:

A book in Home Language, a story set in one's homeland, and/or featuring images and characters that resonate with familiar cultural and geographical/ethnic markers can create a safe space for adult family members and youth to open up conversations about homelands, the people, places, and things that represent cultural histories and social identities of the past. This can represent a 'home' that some younger children have never, and may never, experience. A small book can offer solace to an adult and at the same time offer younger children knowledge, understandings, and authentic participation 
in Home Languages and cultures. Children's texts constitute a less threatening key to opening the door to hidden memories and giving 'voice' to a future. Each book, its words, story and images, is a treasure indeed for negotiating a secure identity!" [17].

In her discussion of the use of English as the medium of instruction in Kenyan schools, Kioko [13] points out the difficulties faced by children who arrive at school with a Home Language which is not English. She suggests that the use of Home Languages in educational settings allows children to navigate the new school environment with more confidence and to bridge learning from home into the new school setting more effectively. In addition, she notes that children are more likely to engage in the learning process when their Home Language is used. Similarly, Bills and Hunter [18] explored the use of Tongan language in mathematics classes for Tongan students aged 11-13 years, showing that the use of Home Language in this context not only enhanced conceptual development but also self-esteem. Daly and Barbour [19] describe the process of teachers in Vanuatu, native speakers of indigenous languages, translating readers into local indigenous languages. This was done to enact the 2012 Vanuatu National Languages Policy, which acknowledges the importance of using a child's first language in early formal education and which proposes that the first two years of education are offered in a child's indigenous language. Interviews with the teachers translating the readers shows that they themselves had experienced many challenges around learning to read in a language that was not their Home Language [19].

\subsection{The Potential of Home Language Children's Literature in Supporting Educational Progress}

The difference between the three settings just described, and the refugee classroom setting in focus in this chapter, is that in the previously described settings there were teachers available whose Home Language was the same as the Home Language of the children in their classroom. By contrast, in a refugee classroom, there are a range of languages, and it is very unlikely that the teacher will know enough of any of them to be able to teach using this medium. While interpreters are available for translating some information, they are not in the classroom every day, sometimes only once a week. This is where the power of children's literature becomes evident. Children's books can bring the Home Language into the classroom, simultaneously performing many functions including (1) validating the status of the language by encouraging the use of the language in the classroom; (2) enabling those children who can read in their Home Language to maintain this skill; (3) enabling parents to share the stories with their children and others in the classroom; and (4) enabling children with other Home Languages to be aware of the languages of their classmates.

Several authors have reported on programmes designed to ensure that migrant and refugee children have access to children's books in their Home Languages. For example, [20] reports on a bilingual family literacy programme delivered to 17 families (90 children) in the United Kingdom and Canada, The programme aimed to promote Home Language literacy while also supporting the learning of English. Some of the resources used in the programme were bilingual children's books in English and the family's Home Language. The researchers document a range of ways in which these children's books were used: Some families read in their Home Language, some read in English, and some read the text in both languages. The researchers noted that, for some families, reading in their Home Language was "a deliberate strategy to maintain their heritage language"; when participants were asked which resources were helpful to use at home, the bilingual books were frequently mentioned. Results showed that, when compared with a control group, the children participating in the bilingual family literacy programme had a statistically significant higher level of literacy skills.

Devos [21] described another programme developed and implemented in Flanders in Belgium, in conjunction with IBBY Flanders. This programme, known as O Mundo, involved the collation of ten books in ten languages spoken by immigrant and refugee children for use in five multilingual primary schools. The books were chosen in consultation with native speakers of these languages, specialists in the country of origin, and a panel of literacy experts, and were shared with the schools in 2013. Challenges faced during the selection process included finding stories which were culturally 
recognisable, while simultaneously avoiding the danger of stereotypes, as well as finding books written in Home Languages which were predominantly oral languages and so did not have a strong written tradition.

The reactions of the schools, teachers, and children to the O Mundo programme in Flanders were evaluated in January and June 2014, and Devos reports that "the teachers were surprised by the overwhelming reactions of the immigrant pupils, by their pride in 'their own' books and the interest they displayed in the languages of the other pupils" (p. 153). Teachers also reported that the use of the books had very positive effects on the children's emotional well-being and self-confidence, "which had a positive effect on their willingness to learn and participate" (p. 155). Parents also seemed to benefit in improved self-esteem when the books in Home Languages were brought into the classroom. Devos noted that these collections (a second set was developed in 2014) were purchased by many schools, but for others they were too expensive, and it was often local libraries who purchased the sets and made them available to local schools. The sets seemed to fill a gap for libraries who were very open to making their collections more multilingual, but who did not have the expertise to find or select these books.

Thus, the literature shows us that not only is it desirable that we support the literacy of refugee children by using their Home Languages in classrooms, it also provides examples of ways in which children's literature can be used to not only support the wider population's awareness of the refugee experience, but also to support Home Language maintenance, learning engagement, and parental involvement in the classroom. With this in mind, we will now describe the experiences of Storylines/NZIBBY in identifying and obtaining books in the Home Languages of Aotearoa/New Zealand refugee children in a refugee resettlement programme.

\section{Setting up the Programme: Challenges and Rewards}

Refugee families arrive in Aotearoa/New Zealand in six intakes throughout the year, and the countries from which each intake of refugees come can differ markedly. The first challenge, therefore, was to establish the Home Languages of the refugee children in order to source appropriate books. Through working closely with the director and teachers at the refugee education centre, a schedule of the most likely Home Languages of the refugees for each intake was established.

We found that books in some of the wide range of Home Languages of the refugee families arriving in Aotearoa/New Zealand were hard to access. Few local bookshops, publishers, schools, libraries, and other educational communities had suitable books. While it was challenging to find sources for procuring the books in these languages, Storylines/NZIBBY, had recently hosted the biennial IBBY Congress in 2016, with delegates from 66 of the 75 IBBY countries. We had developed active and positive relationships with members of other national IBBY sections who could access books in some of the languages of the Aotearoa/New Zealand refugee families. IBBY colleagues provided contacts with publishing companies, bookshops, and individuals, and books in a number of languages were purchased or, in a number of cases, generously donated by IBBY national sections.

Since the funding was received in 2018, over 350 books were sourced in a range of languages including Farsi, Arabic, Tamil, Punjabi, Burmese, Karen, Chin, and Spanish. While books in some of these languages were easy to access, for example, Arabic because of its use in many countries, other languages proved to be extremely difficult to locate in children's book form. We faced challenges locating children's books in languages such as Karen and Chin, spoken by refugees from Myanmar, and North African languages such as Tigrinya and Amharic spoken in Eritrea and Ethiopia, respectively. For refugees from Rohingya, few books exist as their language is predominantly oral, and finding books in the written script Rohingyalish was challenging.

Ensuring that the books were culturally and linguistically acceptable was another challenge. A decision to focus on picturebooks was made because: (1) They were deemed to be more appropriate for families, and for parents and teachers to share with children, or siblings to engage in peer reading contexts; (2) the quality of the texts and images could more easily be assured; and (3) novels, 
junior fiction, and young adult were more likely to have cultural and religious themes, which may have been difficult for us to verify. We were also aware that the illustrations, context, and the language used in the books may evoke negative responses from children who had had traumatic experiences as the result of persecution or war, and such books were avoided.

The books that we purchased, or were donated, in many cases could be assured to be of reasonable literary quality because of the integrity and knowledge of those from whom they were sourced. Books recommended or donated by members of national IBBY sections we could be assured were acceptable, although we did need to be sure that books were apolitical. Interpreters, and other personnel at the refugee centre who were fluent in each of the languages, checked each book to ensure it was well written, non-political, and likely to appeal the children.

Freight costs were high, but were not as great a challenge as anticipated, as these were reduced in many cases through personal conveyancing. Although initial funding was expected to set up the programme, to run it for about a year and then to be supported by funding sourced locally, the IBBYNZ/Storylines was delightfully surprised to be awarded further funding early in 2019 to continue, and extend, the project beyond the initial years.

\section{Teachers' Voices: Use in the Classroom}

Winning funding and locating the relevant books has been an interesting and complex process, which it is important to document. We were also interested in the books being used in the classroom; how they were received by teachers, children, and families; and how they were being used. We had the privilege of discussing these issues with five teachers in refugee education centre classrooms where the books were available. At the time of the interviews, the books in Home Languages had been in the school setting for the three to four 6 week intakes of students. After ethical approval for the research had been gained, a presentation was made to the teachers in the programme about the research and what participation would involve. Five teachers kindly volunteered to be interviewed by one of the authors not involved in the programme funding using a semi-structured interview format [22], which was based around a set of guiding questions (see Appendix A). This format was chosen, rather than a focus group, to allow the individual voices and experiences of each teacher to be fully heard. The interviews (which ranged in length from 13 to 36 minutes) were conducted between July and October, 2019. They were audio-recorded and then transcribed. Participants checked and amended their transcripts, and in the next section a description of the five participants (using pseudonyms), their classes, and a summary of responses related to the questions in the interview are presented below.

\subsection{Teacher Participants and Their Classrooms (Questions 1-3)}

Claire had been teaching for three years and was currently teaching secondary level students. Her 22 class members ranged from early learners of English to advanced English speakers. In her current intake, she had students from Colombia, Myanmar, Afghanistan, Somalia, Ethiopia, and Iraq.

Margaret had been teaching at the school for 18 years. She was primary trained but teaches across all levels. In the year the interviews took place, the school had Swahili speakers from the Congo, Pakistani speakers of Urdu, and Malay speakers.

Maya had been teaching for 18 years and was an Early Childhood teacher. At the time of the interview she had about 19 students who came from Eritrea, Somalia, Pakistan, and Iran.

Patricia had been teaching English to Speakers of Other Languages (ESOL) for the last 18 years, and at the time of the interview was teaching adults and people above 14 years at the preliterate and beginner level of English language proficiency. She had students from Myanmar (several languages), Afghanistan, Colombia, the Congo, and Iraq.

Tim had been working in the school for the last 15-16 years and had worked with children of all ages from 5 years up in that time. At the time of the interview, he was working with children between the ages of 10 and 14 years; his intake included Spanish speaking children from Columbia, 
Arabic speaking children from Syria and Palestine, Afghani children, Sri Lankan children, and children from Myanmar.

\subsection{Ways in Which Books Are Being Used in the Classroom (Questions 4-6)}

Across the five teachers interviewed, it could be seen that the books were being used in a range of ways. Margaret explained that when the Home Language books first arrived at the school, the teachers had thought about having them in every single class, but this is not what happened in the end. For a variety of reasons, they ended up focusing the use of the Home Language books in the middle levels of the programme. At the time of the interview, the teachers had split the books into four groups (for the four whare or classrooms), which were checked in and out as needed in the classroom.

Margaret explained that the books were sometimes put out as one of a range of activities children could choose to do. So far, there had been very successful use of the books. She reported that "the joy of having a book in their own language which they could see...the children were totally engaged, just intrigued to hear a book being read to them in their own language". Margaret explained that, for the first intake of students after the books came to the school, a session of older students reading to children was organised, and in subsequent intakes two similar sessions were organised. In more recent times, they were aiming to have one session per week for the four middle weeks of the six week programme (Weeks 1 and 6 not included). Tim reported making the books available for independent reading and described the children being initially surprised and excited that books in their Home Language were in their new country. Maya, who taught kindergarten aged children, explained that, by the end of the first week of each six week programme, she had introduced book reading (using the Home Language books) during a quiet time at the end of the day.

Another way in which the books had been used in the classroom was to invite adults/parents from the adults' classes to come in and read to the younger children. Tim explained that, the first time, some adults were not that keen. He reflected that maybe they were unsure or felt they might be judged. It is also possible that reading in this way was an unfamiliar activity, but once they knew what was involved, volunteers increased. When the adult readers went back to their classmates and reported how well it had gone, there were more volunteers than were needed for reading to the children. This was good, because it meant there could be several smaller groups, more stories being read, and children could choose who they might prefer to listen to. Tim explained that he went with whatever made the children and adults most comfortable and interested in reading.

A variation on the approach of having adults read to children was described by Tim, who asked the interpreters to read the books to the children. He observed that this was really good because it gave the interpreters something different to do, and it created a bond between them and the children. They were doing something fun and the children were enjoying it. It was a shared experience for them to "use for the next time they had to interpret something they [the children] did not want to hear, such as the rules of the school or if they were in trouble". Tim felt that this experience seemed to change the relationship between interpreters and children. The interpreters usually came in once a week, and there were important facts, explanations, and instructions that needed to be translated in that time, thus opportunities to establish a good relationship between children and interpreters were very important.

As well as the teachers using the Home Language books, some of the older children were observed using the books in specific ways. For example, Claire reported seeing teenagers in her classroom sharing each other's writing systems. "A lot of the teenagers have heard of Arabic but they've never seen Arabic written, or Farsi or Urdu. The teenage unit is really tight so there's a lot of socialising that goes on. And you see them hanging out with each other, showing each other their scripts, and they're really interested...". 


\subsection{Perceived Impact of Home Language Books (Questions 7-10)}

\subsubsection{Impact on Children}

Margaret noted that, when the books were read to the children, there was a high level of engagement, more so than when books were read in English. There was no problem with behaviour when Home Language books were being read. This effect on behaviour was also noted by Claire who described a 'golden hour', when the older students came in to read Home Language books to younger students. During this time, suddenly, any behavioural issues did not occur, apparently because of the children's the engagement with the books. "They [the children] wanted to be there and they wanted to be part of what was happening. They were excited and interested in it, so it makes a big difference". Claire reported that her teenage secondary students had previously explained to her that doing maths is a kind of a break from English in their day, and she could see that reading the Home Language books was a similar break from having to grapple with English: "It's a break from the endless English that's going on and on and on, and often they feel a bit overwhelmed".

Tim noted that, the day before he first made the Home Language books available in his classroom, they had had a session with English language books in the classroom and that, by comparison "the take up and engagement level was that much higher when the books were in a language which some of them could already read". Tim also noted that when the children picked up a book in English they sometimes just had a quick look through the pictures, but when the book was in their Home Language they took time, and were engaged in a different way.

In some sessions, when parents came into the classroom to read books to their children, Margaret reported that the children wanted more and were sad when the book was finished. They appeared to feel happy that someone from their country was reading the book to them. The families whose Home Languages had a very small numbers of speakers were really surprised to see books in their languages.

Tim related an incident in which the use of Spanish fairytales books during a Colombian student's time at the school seemed to have a demonstrable effect on supporting her English language acquisition. Tim explained that the student was "initially difficult to engage, especially in speaking, reading, and writing in English, which she found difficult". However, she was immediately drawn to a book of fairytales in Spanish (that Tim had purchased from a second-hand bookstore). After this experience, she began reading some of the other Spanish language books in the Home Language book collection. Tim noted that she would choose to read either the fairytale book or another book in her Home Language at any available opportunity during class, instead of using computers or playing games like many of her classmates. As time went on, Tim encouraged her to use a bilingual (English/Spanish) dictionary, which again she was attracted to because it contained her native language. She began using this to supplement the English she was learning to write in class. For this particular student, her mother, and her teachers, the progress in her English language acquisition encouraged by the books in her Home Language was extremely pleasing to witness. Tim believes that this may not have occurred without access to the books in her Home Language.

\subsubsection{Impact on Adults/Older Students}

According to Margaret, the effect on the adults reading the Home Language books to children had also developed over time. In the first week, the adults were not sure what to do, but by the second time more than one adult volunteered. Margaret noted that they were reading to small groups of about six. Some held the books up; some read around a table; some of the adult readers, who may have had previous teaching experience, elicited vocabulary from the students. Patricia also noted a range of confidence in reading Home Language books to children. For example, one of her students from Colombia was animated and read the books in Spanish to some of the other Spanish speaking students. Another student enjoyed the role of 'being the teacher'. Margaret noted that sometimes, when parents came in and read the books to their children, the parents said they enjoyed reading to the children because it made the children happy. She reported that, during these sessions, the children 
asked questions and the parents said they enjoyed being with the children; they liked the way the children really listened, and it was clear that the children were using their imagination.

Tim noted that, when adults came in to read Home Language books to the children, the children loved having family members in their classroom. The children were learning the importance of reading at home and this experience was simultaneously showing the parents how important reading to their children was. From the very first time they came into the classroom to share the books, Tim noted the pride the children took in having a family member coming in to read a Home Language book at the school. Maya related a time when a parent came to her with a book (from the Home Languages collection) and asked her to show him how to read a book to his child. He wanted to know things like when to stop, and when to emphasise. At lunchtime he came back and they practised reading the book. As Maya explained, "he was so happy doing that. He was so excited and proud that he could read it for everyone. It was very touching when he came and said he hadn't been able to read much. He wanted to know if he was doing it 'right'". She said her experience was that, in the Early Childhood setting, the parents needed to be encouraged, and having the books in their home language meant they could learn to read to their family.

\subsubsection{Challenges}

The challenges around bringing the Home Language books into the refugee classrooms reported by the teachers in the early stages of the programme revolved around (1) sometimes not having a book in the language of every child in the class, (2) managing access to the books across the school, and (3) having more books for a wider age range.

\subsection{Range of Languages}

One of the difficulties encountered at the start of the programme was that the books were initially sourced in Home Languages for the current intake of families and their language in the refugee education centre. However, as reported earlier, in each new intake there were speakers of new languages and this was very difficult for the children for whom there were no books. Margaret noted that, for example, at first they did not have books for Urdu speakers. The Urdu speaking children were disappointed, and the parents even more so. This meant that the teachers did not bring the books in Home Languages out as often because some children might have felt excluded. Margaret explained "that's one thing we try very hard to do here; everyone has an equal voice. Even if there is only one speaker of a language, they have an interpreter." In one intake, the school had a group of children who were bilingual French and Swahili speakers from the Congo, and as there were not yet any Swahili books. Margaret went into the local library and got French books which could then be translated into Swahili, and the families were very pleased. IBBY was soon able to help the IBBYNZ/Storylines team to source some of the books in the missing Home Languages, and the children were thrilled when these arrived. Maya noted that she had considered not handing out the Home Language books if not all languages were available for her students, but she has always handed out what she had and explained to the others why books in their languages were not available.

Tim also noted that it was difficult when books in the Home Languages of all children were not available. When this happened, he explained to the children, through the interpreters, the reason for this. Due to the difficulty in sourcing books in some Home Languages (as noted above), there was sometimes a lag in the books arriving, which could exceed the six week programme of which that group of children were a part. One of the strategies used by Tim when books were not available in the Home Languages of some children was finding people who could read English language books and simultaneously translate into the target Home Language.

\subsection{Access to Books in Class and after School}

Margaret, Tim, and Patricia both noted that another challenge was that the students could not take the Home Language books home with them. Tim said that parents of the children had asked if books 
in Home Languages could be taken home. He commented that the refugee education centre promotes both reading at home, and maintaining Home Language, so being able to take Home Language books home with them would support both kaupapa (aims/beliefs). Tim did make an exception and allowed one parent who had been involved in coming into classrooms to read Arabic books to children to take home a book each night to read to her daughter. He explained, "After coming to the primary class to read books to children in Arabic, one of the parents (and her daughter) asked if they could borrow an Arabic book each night so that they could continue to do this at home. As a parent was involved and the primary student herself was a responsible child, we felt comfortable with a system that involved that student's teacher checking a book out to her each day and checking it back in on the next. This girl and her mother had been living outside of their homeland all of the young girl's life and as a result had not often had the opportunity to read books in their Home Language. They were very appreciative of being able to do so".

Claire also noted that her teenage students would have loved to take books home. "It's so beautiful to have a book in your own language; the children want to take them home". She described the balance they had to achieve in allowing the students to use the books, but not being able to allow them to take the books home. She recounted that they explained to the students that the books needed to be there for the next group of students coming through.

Access to the books during school time was another issue which arose because of the value of the books, which meant they were at times stored away and not always available for incidental reading. Tim noted how great it would be to have books in Home Languages in public libraries and perhaps a teaching resource library which families could access during their time at the refugee centre.

\subsection{More Books for Teenagers}

Claire was the only teacher interviewed who was teaching older teenaged children, and she noted that, in addition to having more books available so that the children could take them home, it would be good to have books at a suitable level and content for teenagers. "Maybe they are reading beginners but they're not having to read 'baby books'...because teenagers usually prefer not to be seen reading young children's' books. Having books for teenagers would be so amazing". She suggested having bilingual books with Home Language and English text to allow understanding of longer texts.

\subsection{Ideas for the Future}

All the teachers were really appreciative of the affordances of having books in Home Languages available for their students. As well as opening up new ways of supporting Home Language maintenance and development for their students, a value that is already embraced within refugee education centres, it opened up numerous other possibilities. A recurrent theme in the interviews was finding ways to make the books more freely available. An after-school library where children and parents could browse at their leisure, as well as having the books freely accessible at all times within the classroom, were ideas suggested by the teachers, and indeed, since the time of the interviews, we have been told this has been made possible. Books in a wider range of languages, and at a range of levels suitable for teenagers, would ensure that children in every classroom could access books in their Home Languages more freely. We also discussed providing the children with two or three books in their Home Language to take with them to whichever part of Aotearoa/New Zealand they settle in after leaving the six week resettlements programme. Such books could also be used to encourage the school librarian and classroom teacher in the school they attend to find more such books.

\section{Discussion}

In this discussion, we focus on some of the challenges, as well as the affordances, of the IBBYNZ/Storylines project supplying Home Language books for children in the refugee education centre, making links to the existing literature. 


\subsection{Challenges}

Locating children's books in a range of languages, some of which are not spoken by large communities and which did not have a tradition of producing children's books was, as described above, a challenge. As with the O Mundo programme in Belgium [21], the support of IBBY colleagues and the contacts they have shared has enabled a large number of appropriate books to have been acquired for the IBBYNZ/Storylines-Yamada project. IBBY colleagues worldwide have also helped in checking the content and quality of these books with native speakers of each language. The challenges for teachers in ensuring the availability of the books within their teaching context, and strategies used to attend to the needs of some children who did not have books in their Home Languages, do not appear to be documented elsewhere. In this study, the strategies of asking readers to simultaneously translate from the language in which the book is written to a particular Home Language and finding appropriate books from public libraries or secondhand book shops have been documented. It is planned that these findings will be explored further in follow-up interviews with the teachers. The creation of text for silent picturebooks (or visual narratives) is an avenue not mentioned by teachers in this study, but one which may warrant further investigation [23]. Such creation of living materials from static learning materials such as books has been documented in programmes preparing teacher educators in refugee responsive pedagogy [24]. Documenting and encouraging teachers in the development of such strategies, rather than requiring certain strategies to be used, is consistent with the desire of the IBBYNZ/Storylines to ensure that teachers in the refugee education centre have ownership of the way in which Home Language books are used within their teaching practice.

\subsection{Affordances}

The overarching theme relating to the affordances of this programme is that there is so much more going on than children getting books in their Home Languages. To begin with, the pride and joy the children reportedly displayed in encountering books in their Home Languages was very similar to that reported by Devos [21] in the O Mundo programme. Not only did children take pride in their own language, they also showed interest in the languages of their classmates. There were also many examples of ways in which the teachers reported observing the children engaging positively with the books, which we can assume will have positive educational benefits. While this study does not report any specific literacy data showing improved literacy outcomes, the vignette of the Spanish speaking student, whose English language progress appeared to be strongly linked to her engagement, firstly with Spanish fairytales and then with other Home Language books provided as part of this programme, would seem to support the potential for many such positive outcomes. Anderson, Friedrich, and Kun's [20] Home Language biliteracy programme reports similar outcomes.

Additionally, children were thrilled to see their family members come into the classroom to share books, which leads us to a second very important positive outcome of the Home Language Books programme: Parental engagement. This is similar to that found in the Canadian-British Home Language Literacy programme described by Anderson, Friedrich, and Kun [20]; likewise, Devos [21] described improved self-esteem amongst parents. In their work with children's literacy development using iPads to create ebooks, Rowe and Miller [25] also found the use of heritage language translations supported engagement with parents. Parental engagement was certainly evident in the incident reported above where a father very deliberately practised reading techniques so he could share the books with his children and join in reading books to children in the classroom.

At a wider community level, it is hoped that this programme, like the O Mundo programme [21], will lead to the books being made available to the refugee children when they move to the city in which they will be settled after the six week resettlement programme. While many public libraries in Aotearoa/New Zealand are already developing collections to meet the needs of migrant and refugee communities [26], it is less common for a school library to be able to do this, due to smaller numbers of children in each school. However, if refugee children are sent to their new schools with a few books 
in their Home Languages, as suggested by several teachers interviewed, the development of such resources may be supported.

If the development of such collections in public and school libraries is achieved, the Home Language books not only provide a mirror for the refugee children to see themselves and read stories reflecting their cultural identity, their very presence in school and public libraries simultaneously provides a window for children and their families from the dominant language to develop their awareness of other languages and ways of being in the world, as noted by Brookes [6] and Arizpe [7]. As mentioned earlier, Principle 4 of the International Literacy Association's ten principles of the Children's Right to Read campaign, stating that "children have the right to read texts that mirror their experiences and languages..." is for all children, not just children whose language is the dominant language of the society in which they live. Realising that Aotearoa/New Zealand refugee children are New Zealanders with the same rights to hearing their stories and having literacy in their Home Languages is an important part of the gift that Home Language books can provide in the community.

A limitation of this research is the small number of teachers interviewed and the early stage of the introduction of the books at which the interviews were conducted. Anecdotal reports since the interviews indicate that the ways in which the books are used in the refugee classrooms are continuing to develop and flourish. We have heard, for example, that since our interviews the Home Language books are now available at all times in the classrooms and nearly all language groups are catered for. While a very small number of books have gone missing, it was apparent they had been taken home. While the loss of books could be considered a challenge, it is also an indication of the success of Home Language books in the classroom. The joy of a book about a child's homeland and in his/her Home Language is evident; and keeping it close may be a form of reassurance that their 'new home' has objects that are familiar and valued.

\subsection{Future Directions}

There are many ways in which this research can be developed in the future, including initially re-interviewing the teachers in this programme over the next 12 to 18 months to see how their practices have developed using Home Language books over time. Interviewing children and parents for their perspectives would also be hugely valuable, but this was avoided due to the vulnerable status of refugees within their first six weeks of being resettled in a new and strange country. We think that interviews with parents and children retrospectively a few years into their resettlement is a more probable and ethical possibility. Being in the classroom to observe the ways in which the books are used and received by teachers, students, and their families would also be of interest, and a way of avoiding the limitations of reported observations.

Following the outcomes of the present study, several plans have been made to develop the programme, including to (1) establish a library of books which are duplicates of those used in the classroom on site at the refugee education centre from which families can borrow; (2) continue discussions with the refugee education centre and the Library Association of Aotearoa/New Zealand, as well as the Red Cross, who have responsibility for oversight of refugee settlement in their new communities, to encourage the inclusion of Home Language books in community libraries. As these two extensions of the project get underway, they will be documented and evaluated using a collaborative action research approach.

\section{Conclusions}

This article has described the development and initial implementation of a programme providing books in the Home Languages of refugee children in a refugee education centre in Aotearoa/New Zealand. Interviews with five volunteer teachers in the programme identified the ways in which the books were being used, the impact of the books on the children and adults, and the challenges the teachers identified in relation to the range of languages present, access to the books outside of the classroom, and including books for teenagers. The challenges and affordances of the programmes 
have been discussed in light of literature describing the importance of Home Language education, the potential of children's books, and the experiences of similar programmes. Future ideas for developing the programme based on reflections and suggestions from teachers using the books have been identified. Certainly, the reception of books in Home Languages has been overwhelmingly positive; the challenges faced are interpreted as opportunities to shape the future development of the programme by purchasing books in more languages for a wider age group and making these available freely within classrooms, libraries, and refugees' new homes. All children have the right to read in their Home Language stories which reflect their cultural heritage and identity [15]. This has implications for their future educational success and for the maintenance of the Home Language. The prime purpose of the programme described in this article is to ensure that refugee children, who face many challenges as they settle in their new home, have this right protected.

Author Contributions: L.L. was involved in procuring the IBBY-Yamada funding to purchase the Home Language books, and N.D. conducted the interviews and their initial thematic analysis. Both authors contributed equally to the writing of this article. All authors have read and agreed to the published version of the manuscript.

Funding: Funding for the purchase of the Home Language books referred to in this article was from the IBBY-Yamada Foundation in 2018 and 2019.

Acknowledgments: The authors would like to gratefully acknowledge the IBBY-Yamada Foundation for funding the purchase of the Home Languages books referenced in this article. We also sincerely thank the teachers in the refugee education programme who participated in this research.

Conflicts of Interest: The authors declare no conflict of interest.

\section{Appendix A}

1. How many years have you been teaching at the Mangere Refugee Resettlement School?

2. What levels do you teach?

3. Tell me something about your learners: age group/country of origin/languages spoken or able to read in

- Did they have access to story books previously?

- Did they read books or tell stories to one another in their homes prior to coming to NZ?

- What impact did you notice on parents or older siblings who were reading the stories?

4. In what ways have you used children's books in your classroom practice?

5. What were the children's/learners' initial reactions to the books in their Home Languages? Has this changed over the time they have been here?

6. How and when have you seen them being used? By the children/learners? By the parent? By older siblings?

7. How do you feel about having these books in your classroom? Why do you feel that way?

8. Have you noticed any changes on language use in the classroom which you think could be as a result of the books?

- $\quad$ Please expand

9. What impact do the books have on the children's/learners' learning engagement?

10. Have you seen any evidence of a positive impact on the literacy of the children/learners? What do you think might be the benefits of the books for children's/learners' literacy learning? What problems might arise in the use of the books in the classroom?

- If yes, please expand.

11. Do you have any specific incidents involving the books which you could share with us? 


\section{References}

1. Adern, J.; Lees-Galloway, I. Refugee Quota Increases to 1500 in 2020. 2018. Available online: https: //www.beehive.govt.nz/release/refugee-quota-increases-1500-2020 (accessed on 15 September 2020).

2. IBBY-Yamada Fund. The Children's Right to Become a Reader. 2020. Available online: https://www.ibby.org /awards-activities/activities/ibby-yamada-fund (accessed on 15 September 2020).

3. Ministry for Culture and Heritage. History of the Māori language. 2020. Available online: https://nzhistory. govt.nz/culture/maori-language-week/history-of-the-maori-language (accessed on 15 September 2020).

4. Hunter, J.; Hunter, R.; Bills, T.; Cheung, T.; Hannant, B.; Kritesh, K.; Lachaiya, R. Developing empathy for Pāsifika learners within a Aotearoa/New Zealand context: Attending to culture and values. Aotearoa/N. Z. J. Educ. Stud. 2016, 51, 197-209.

5. Pulinx, R. The Dynamics of Teachers' Beliefs about Language, Citizenship and Social Interactions. Echoes of Monolingualism in Flemish Classrooms. Unpublished Ph.D. Thesis, University of Ghent, Ghent, Belgium, 2017.

6. Brooking, T. Navigation to safety: Exploring a human rights focus in the curriculum as a pedagogical tool for developing empathy and validating refugee children's experiences. In Children's Literature in a Multiliterate World; Daly, N., Limbrick, L., Dix, P., Eds.; Trentham Press: London, UK, 2018; pp. 59-75.

7. Arizpe, E. Migrant shoes and forced walking in children's literature about refugees: Material testimony and embodied simulation. Migr. Stud. 2019, mnz047. [CrossRef]

8. Bishop, R.S. Mirrors, windows and glass sliding doors. In Perspectives: Choosing and Using Books for the Classroom; oxford academic: Oxford, UK, 1990; Volume 6, pp. ix-xi.

9. Christensen, L. Finding voice: Learning about language and power. Voices Middle 2011, 18, 9-17.

10. Ball, J.; Enhancing Learning of Children from Diverse Language Backgrounds: Mother Tongue-Based Bilingual or Multilingual Education in the Early Years. Paper 2010/ED/BAS/ ECCE/PI/1 prepared for United Nations Educational, Scientific and Cultural Organisation. 2011. Available online: http://unesdoc.unesco.org /images/0021/002122/212270e.pdf (accessed on 15 September 2020).

11. Cummins, J. Pedagogies of Choice: Challenging Coercive Relations of Power in Classrooms and Communities. Int. J. Bilingual Educ. Biling. 2009, 12, 261-271. Available online: https://www-tandfonline-com.ezproxy.waik ato.ac.nz/doi/full/10.1080/13670050903003751 (accessed on 15 September 2020). [CrossRef]

12. Cummins, J.; Bismilla, V.; Cohen, S.; Giampap, F.; Leoni, L. Timelines and lifelines. Rethinking literacy instruction in multilingual classrooms. Orbit 2005, 36, 22-26.

13. Kioko, A. Why Schools Should Teach Young Learning in Home Language, Voices Magazine, British Council. 2015. Available online: https://www.britishcouncil.org/voices-magazine/why-schools-should-teach-younglearners-home-language (accessed on 15 September 2020).

14. Cummins, J.; Hornberger, N.H. Bilingual Education, 2nd ed.; Springer: New York, NY, USA, 2008.

15. International Literacy Association. Children's Rights to Excellent Literacy Instruction. 2019. Available online: https://www.literacyworldwide.org/docs/default-source/where-we-stand/ila-childrens-rights-to-e xcellent-literacy-instruction.pdf (accessed on 15 September 2020).

16. Brown-Hamilton, T. The Difference between Assimilation and Integration in the Classroom. The Atlantic. 16 May 2016. Available online: http://www.theatlantic.com/education/archive/2016/05/balancing-integrationand-assimilation-during-the-refugee-crisis/482757/ (accessed on 15 September 2020).

17. Harvey, N.; (University of Auckland, Auckland, New Zealand). Personal Communication, 2018.

18. Bills, T.; Hunter, R. The role of cultural capital in creating equity for Pāsifika learners in mathematics. In Mathematics Education in the Margins (Proceedings of the 38th Annual Conference of the Mathematics Education Research Group of Australasia); Marshman, M., Geiger, V., Bennison, A., Eds.; MERGA: Sunshine Coast, Australia, 2015; pp. 109-117.

19. Daly, N.; Barbour, J. 'Because, they are from here. It is their identity, and it is important': Teachers' understanding of the role of translation in vernacular language maintenance in Malekula, Vanuatu. J. Biling. Educ. Biling. 2019. [CrossRef]

20. Anderson, J.; Friedrich, N.; Kun, J.E. Implementing a Bilingual Family Literacy Program with Immigrant and Refugee Families. In The Case of Parents as Literacy Supporters (PALS); University of British Columbia: Vancouver, BC, Canada, 2011. 
21. Devos, E. 'I can read this, Miss! It's my language!': Reflections on a multilingual reading programme in Flanders. In Children's Literature in a Multiliterate World; Daly, N., Limbrick, L., Dix, P., Eds.; Trentham Press: London, UK, 2018; pp. 147-160.

22. Cohen, L.; Manion, L.; Morrison, K. Research Methods in Education; Taylor and Francis Group: Oxford, UK, 2011.

23. Mcgillicuddy, A. Breaking down Barriers with Wordless Picturebooks: "The Silent Books Exhibition, from the World to Lampedusa and Back". Stud. Arts Humanit. J. 2018, 4, 93-108. [CrossRef]

24. Kostoulas-Makrakis, N.; Makrakis, V. Developing student-driven learning activities to promote refugee quality education through the CARE methodology. Int. J. Early Years Educ. 2020, 28, 176-188. [CrossRef]

25. Rowe, D.W.; Miller, M.E. The affordances of touchscreen tablets and digital cameras as tools for young children's multimodal multilingual composing. In The Case of the iPad. Mobile Literacies in Education; Burnett, C., Merchant, G., Simpson, A., Walsh, M., Eds.; Springer: Singapore, 2017; pp. 159-178.

26. Immigration New Zealand. Superdiversity and the Public Library. 2020. Available online: https://www.im migration.govt.nz/about-us/media-centre/newsletters/settlement-actionz/actionz5/superdiversity-and-the-pu blic-library (accessed on 15 September 2020).

(C) 2020 by the authors. Licensee MDPI, Basel, Switzerland. This article is an open access article distributed under the terms and conditions of the Creative Commons Attribution (CC BY) license (http://creativecommons.org/licenses/by/4.0/). 